SPOR BİLIMLERİ ARAŞTIRMALARI DERGİSI

Journal of Sport Sciences Researches

http://dergipark.gov.tr/jssr

ISSN: 2548-0723

\title{
Oyun ve Fiziki Etkinlikler Dersinin Çocuklarda Seçilmiş Motorik Özellikler Üzerine Etkisi
}

\author{
Ece ONGÜL ${ }^{1 *}$, Betül BAYAZIT ${ }^{2}$, Ozan YILMAZ ${ }^{1}$, Mustafa GÜLER ${ }^{1}$ \\ ${ }^{1}$ Kocaeli Üniversitesi, Sağlık Bilimleri Enstitüsü, Beden Eğitimi ve Spor Anabilim Dalı \\ ${ }^{2}$ Kocaeli Üniversitesi, Spor Bilimleri Fakültesi, Spor Yöneticiliği Bölümü
}

$\ddot{O} \mathbf{z}$

Orijinal Makale

Bu çalışmada, oyun ve fiziki etkinlikler dersinin çocuklarda seçilmiş motorik özellikler üzerine etkisinin incelenmesi amaçlanmıştır. Çalışmaya, Kocaeli ilinde bulunan Özel Eğitim Kurumunun ilköğretim birinci kademesinde okuyan 9-10 yaşlarında olan n=149 (erkek=66, kız=83) 3. ve 4. sınıf öğrencisi gönüllü olarak katılmıştır. Yapılan ölçümler; boy, vücut ağırlığı, kulaç uzunluğu, esneklik, durarak uzun atlama ve sağlık topu firlatma ölçümlerinden olușmuștur. Calıșmadaki etkinlikler, spor salonu, yüzme havuzu ve buz pateni alanlarında gerçekleştirilmiştir. İlk test ve son test arasında 28 hafta süresince eğitim müfredatında bulunan buz pateni, yüzme ve eğitsel oyunlardan oluşan sportif etkinlikler uygulanmıştır. Üç haftada bir dönüşümlü olarak spor salonu, yüzme havuzu ve buz pateni alanları kullanılarak ders içeriklerine uygun olarak sportif etkinlikler gerçekleştirilmiştir. Uygulamalar beden eğitimi öğretmeni tarafından gerçekleştirilmiştir. Ölçümler araştırmacılar tarafından uygulanmıştır. Çalışmada elde edilen veriler istatistiki analizi SPSS 21.0 programında yapılmıștır. Verilerin çözümlenmesinde tanımlayıcı istatistik, Mann-Whitney U Testi ve Wilcoxon İşaretli Sıralar Testi uygulanmıştır. Anlamlılık düzeyi $\mathrm{p}<0.05$ olarak belirlenmiştir. Çalışma sonucunda, durarak uzun atlama, otur uzan eriş ve sağlık topu firlatma değişkenlerinde istatistiksel olarak anlamlı farklılık bulunmuştur $(\mathrm{p}<0,05)$.

\section{The Effect on the Selected Motoric Characteristics of Children in the Game and Physical Activities Lesson}

\begin{abstract}
In this study, it is aimed to examine the effect of game and physical activity lessons on selected motoric characteristics in children. $\mathrm{N}=149($ male $=66$, female $=83)$ third and fourth year students attending the Special Education Institution in Kocaeli province participated voluntarily in the first grade of elementary school. Measurements made; Height, body weight, flare length, flexibility, standing long jump and throwing health ball. Activities were conducted in the gym, swimming pool and ice-skating areas. The first test and the last test were performed of sports activities consisting of ice skating, swimming and educational games in the education curriculum for 28 weeks. Every three weeks, sportive activities were carried out in accordance with the course contents, using gymnasium, swimming pool and ice patrol areas alternately. The practices were carried out by the physical education teacher. Measurements were applied by researchers. The statistical analysis of the data obtained in the study was carried out in the SPSS 21.0 program. In the analysis of the data, descriptive statistics, Mann-Whitney U Test and Wilcoxon Marked Ranks Test were applied. Significance level was determined as $p<0.05$. As a result of the study, statistically significant difference was found in the variables of long standing jump, sitting reach and health ball throwing $(\mathrm{p}<0,05)$.
\end{abstract}

Original Article

Gönderi Tarihi: 28.04 .2017

Kabul Tarihi: 16.06.2017

Online Yayın Tarihi: 16.06.2017

DOI: $10.25307 /$ jssr.309716

\author{
Psikomotor, \\ beceri, \\ fiziki etkinlikler \\ Anahtar kelimeler:
}

* Sorumlu Yazar E-mail: eceongul@ @otmail.com, Tel: +905388489288 


\section{GíRiş}

İnsan canlı bir varlık olarak gelişimini sürdürürken bulunduğu ortamda hareketlilik içerisindedir (Yüzgül ve Müniroğlu, 2001: 343-356). Bu yüzden, çocuklarda hareket etmek ister. Bu nedenle planlanan etkinliklerde çocukların hareketliliği sağlanmalıdır. Çocuklara hareket ederek öğrenerek zaman geçirebileceği bir oyun ortamı yaratılmalıdır (Çelik, 2016: 180-181). İlköğretimde sekiz yıl boyunca uygulanan beden eğitimi dersleri özellikle ilköğretimin 1. Kademesinde oyunlar şeklinde uygulanmaktadır. Oyun kavramının temelinde de hareket becerilerinin kazanılması vardır. İnsan yaşamını daha sağlıklı ve nitelikli şekilde sürdürebilmek için harekete etmeye ihtiyaç duyar (Koç ve Tekin, 2011: 9-17). İlköğretim büyümenin ve beden gelişiminin en hızlı olduğu dönemdir. İlköğretim eğitim bakımından çok fazla önem taşıdığı gibi, fizyolojik gelişim devrelerini etkilemekte ve çocuğun hem fiziksel gelişiminde hem de sosyal davranışlarında çok önemli süreçler olarak karşımıza çıkmaktadır (Gülüm, 2008:7).

Kompleks becerilerin büyük bir bölümünün asıl hareket parçaları, oyunlardan ve hareket parçalarından uyarlanmıştır. Bu temel hareketler çocuğu ileriki dönemlerdeki edineceği spor becerilerinin öğrenilmesinde avantajlı duruma getirecektir. Temel motor hareketler dönemi desteklenen bir çocuk için motor becerileri kazanmak daha kolay ve etkili bir biçimde gerçekleşeceği gibi daha karmaşı becerilere de olumlu biçimde aktarabilmesi düşünülmektedir (Altınkök, Vazgeçer ve Ölçücü, 2013:74-78).

Motor gelişim terimi ile psiko-motor gelişim terimi sık sık birbirinin yerine kullanılır. Psikomotor gelişim, yaşam boyu devam eden bir süreç olup motor becerilerde azalma ya da yeni bir becerinin kazanılması gibi tüm fiziksel değişmelerle ilgilenir. Çocukların motor gelişimi, hareket yeteneklerinin gelişim ve fiziksel yeteneklerin gelişimini kapsar. Hareketin hassaslığının temelinde motor becerileri sınıflama iki kategoride oluşur: Kaba motor beceriler ve ince motor beceriler. Kaba motor beceriler büyük kasları içermesiyle kategorize edilir ve amaç ince motor becerilerde olduğu gibi hassas bir şekilde bir işi yapmak veya hareket etmek değildir. Yürümek, zıplamak, firlatmak, sıçramak gibi temel motor beceriler bu grupta yer alır (Kuru ve Köksalan, 2012: 37-49).

Psiko-motor gelişim ise fiziksel büyüme ve gelişme ile birlikte beyin omurilik gelişimi sonucu organizmanın isteme bağlı olarak hareketlilik kazanmasıdır. Bu süreç anne karnından itibaren başlamaktadır. Bebeğin doğum öncesi başlayan hareketliliği doğum sonrası daha da artmaktadır. Yaşamın ilk aylarını anne karnındaki pozisyonuna benzer şekilde uykuda geçirirken, ikinci aydan itibaren yavaş yavaş çevreyle etkileşime girmeye başlamaktadır. Oyun aktivitelerinde motor tepkilerin denenmesi süratli, akıcı ve doğru motor becerilerin kazanılmasına yol açmaktadır. Oyun süresince çocuk, kendi bedeninin dünya üzerindeki etkisini ve kontrolünü öğrenmektedir. Bu bilgilere dayanarak oyun aktivitelerinin çocuğun psiko-motor gelişimi üzerinde önemli bir etkiye sahip olduğu ifade edilebilir (Çelik ve Şahin, 2013: 467-478). 
Oyun ve fiziki etkinlikler yetişmekte olan nesillerin fiziksel, zihinsel, duygusal ve sosyal gelişimini amaç edinen, genel eğitimin tamamlayıcısı ve ayrılmaz bir parçası olarak görülen bilinçli ve planlı faaliyetlerdir (Demirci ve Demirci, 2014: 25-34). Gray ve Judy (2003) çocukluk döneminde oyun etkinliklerine katılan çocukların, ilköğretim döneminde hareket becerilerinin kazanılmasında daha başarılı olduğunu ifade etmiştir. Aynı zamanda Jimmy (2003) çocukların ileriki yaşlarda daha sağlıklı ve bilinçli olacağı belirtilmiştir. Bu bağlamda çalışmamızda, oyun ve fiziki etkinlikler dersinin çocuklarda seçilmiş motorik özellikler üzerine etkisinin incelenmesi amaçlanmıştır.

\section{YÖNTEM}

\section{Araştırma Modeli}

$\mathrm{Bu}$ araştırmada deneysel modellerden "öntest-sontest kontrol grupsuz model" kullanılmıştır. Deney grubuna, oyun ve fiziki etkinlikler dersi kapsamında 28 hafta süresince buz pateni, yüzme ve eğitsel oyunlar uygulanmıştır. Araştırmada kontrol grubu bulunmamaktır.

\section{Çalışma Grubu}

Araştırmaya, Kocaeli ilinde bulunan Özel Eğitim Kurumunun ilköğretim birinci kademesinde okuyan 9-10 yaşlarında olan $n=149$ (erkek=66, kız=83) 3. ve 4. sınıf öğrencisi gönüllü olarak katılmıştır.

Tablo 1. Boy, vücut ağırlığı, kulaç uzunluğu ön test - son test ölçüm bilgileri

\begin{tabular}{|c|c|c|c|c|c|}
\hline Değişken & & Cinsiyet & $\mathbf{N}$ & Ort. & SS \\
\hline \multirow{4}{*}{ Boy } & \multirow{2}{*}{ Ön Test } & Erkek & 66 & 137.24 & 6.50 \\
\hline & & Kadın & 83 & 137.23 & 7.28 \\
\hline & \multirow{2}{*}{ Son Test } & Erkek & 66 & 139.94 & 6.40 \\
\hline & & Kadın & 83 & 140.31 & 8.01 \\
\hline \multirow{4}{*}{ Kilo } & \multirow{2}{*}{ Ön Test } & Erkek & 66 & 31.42 & 7.19 \\
\hline & & Kadın & 83 & 31.49 & 7.22 \\
\hline & \multirow{2}{*}{ Son Test } & Erkek & 66 & 32.64 & 6.48 \\
\hline & & Kadın & 83 & 33.20 & 8.01 \\
\hline \multirow{4}{*}{$\begin{array}{c}\text { Kulaç } \\
\text { Uzunluğu }\end{array}$} & \multirow{2}{*}{ Ön Test } & Erkek & 66 & 127.73 & 6,88 \\
\hline & & Kadın & 83 & 126.39 & 8.10 \\
\hline & \multirow{2}{*}{ Son Test } & Erkek & 66 & 134.02 & 7.98 \\
\hline & & Kadın & 83 & 131.94 & 18.97 \\
\hline
\end{tabular}

\section{Veri Toplama Aracı}

Katılımcıların boy, vücut ağırlığı, kulaç uzunluğu, esneklik, durarak uzun atlama ve sağlık topu firlatma ölçümleri alınmıştır.

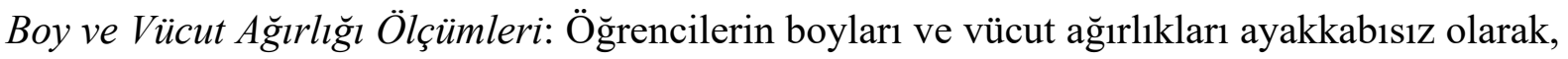
eşofman ile ölçüldü. Ağırlık ölçümünde Oncomed marka sc-101 model baskül ve $0,1 \mathrm{~cm}$ hassasiyette boy ölçer kullanılmıştır. 
Kulaç Uzunluğu Ölçümü: Ayakta, vücut duvara yaslanmış şekilde, kollar yere paralel açılmış pozisyonda, orta parmak uçları (acromelion) arasındaki mesafe ölçülmüştür. (Bu ölçüm sırasında normal anatomik duruş uygulanmıştır).

\section{Psikomotor Beceri Düzeyleri Ölçüm Metotları}

Esneklik Ölçümü: Otur - eriş testi kullanılmıştır. Ölçümler için özel olarak imal ettirilen test sehpası; $35 \mathrm{~cm}$ uzunluğunda, $45 \mathrm{~cm}$ genişliğinde $32 \mathrm{~cm}$ yüksekliğinde, standartlara uygun şekilde imal ettirilmiştir. Sehpaların üst yüzey ölçüleri, $55 \mathrm{~cm}$ uzunluk, $45 \mathrm{~cm}$ genişlik şeklindedir. Üst yüzey, ayakların dayandığı yüzeyden $15 \mathrm{~cm}$ daha dişarıdadır. $0-50 \mathrm{~cm}$ 'lik ölçüm cetveli yer almaktadır. Ölçümler 2 tekrar şeklinde yapılıış ve en iyi derece alınmıştır.

Durarak Uzun Atlama: Kaygan olmayan bir zeminde, zeminin her iki tarafina, yapışarak yere sabitlenmiş, 250 cm'lik ölçüm cetvelleri kullanılarak ölçümler alınmıştır. Ölçüm deneğin başlangıç çizgisindeki ayak parmak ucuyla, atlayıp düştüğü yerdeki ayak topuğu arasında yapılmıştır. İki denemeden sonra en iyi derece alınmıştır.

Sağlık Topu Fırlatma: Deneğin çift kolla birlikte, 1 kg ağırlığındaki sağlık topunu firlatması neticesinde elde edilen uzaklığın cm cinsinden değeri esas alınmıştır. İki firlatma sonunda en iyi derece esas alınmıştır.

\section{İşlem Yolu}

Oyun ve Fiziki Etkinlikler Ders Programının Iç̧eriği: Araştırma uygulanmadan öğrencilere araştırmanın içeriği, kapsamı ve amacıyla ilgili bilgi verilmiştir. Etkinlikler, spor salonu, yüzme havuzu ve buz pateni alanında gerçekleştirilmiştir. Ön test ve son test arasında 28 hafta süresince eğitim müfredatında bulunan buz pateni, yüzme ve eğitsel oyunlardan oluşan sportif etkinlikler uygulanmıştır. Çalışmada öğrencilerin uygulayabileceği lokomotor, manipulatif ve statik-dinamik dengeleme hareketleri çeşitlendirilerek uygulanmıştır. Buz pateni; durduğu yerde sıçrama, paralel kayma, paralel kayarken sıçrama, öne kayma, geri kayma vb., yüzme; suya uyum çalışmaları, suda nefes kontrolü çalışmaları, suda kayma ile serbest ayak vuruş, serbest kol çekişi, serbest teknik ile mesafe kat etme vb., eğitsel oyunlar; basketbol ve voleybol branşına özgü eğitsel oyunlar, eğlenceli atletizm oyunları vb. Üç haftada bir dönüşümlü olarak spor salonu, yüzme havuzu ve buz pateni alanları kullanılarak ders içeriklerine uygun olarak etkinlikler gerçekleştirilmiştir. Uygulamalar beden eğitimi öğretmeni tarafından gerçekleştirilmiştir. Ölçümler araştırmacılar tarafında yapılmıştır.

\section{Verilerin Analizi}

Araştırmada elde edilen verilerin istatistiki analizi SPSS 21.0 programında yapılmıştır. Verilerin çözümlenmesinde tanımlayıcı istatistik ve shapiro-wilk normallik testi sonucunda normal dağılım göstermediğinden dolay1 "non-parametrik" testlerden, Mann-Whitney U Testi ve Wilcoxon İşaretli Sıralar Testi uygulanmıştır. Karşılaştırmalar için anlamlılık düzeyi 0.05 olarak alınmıştır. 


\section{BULGULAR}

Tablo 2. Farklı değişkenlerin cinsiyet değişkenine göre mann-whitney u testi sonuçları

\begin{tabular}{|c|c|c|c|c|c|c|c|}
\hline Değişken & & Cinsiyet & $\mathbf{N}$ & Ort. & SS & $\mathbf{Z}$ & $\mathbf{p}$ \\
\hline \multirow{4}{*}{$\begin{array}{c}\text { Durarak Uzun } \\
\text { Atlama }\end{array}$} & \multirow{2}{*}{ Ön Test } & Erkek & 66 & 115.76 & 27.00 & \multirow{2}{*}{-1.501} & \multirow{2}{*}{.133} \\
\hline & & Kadin & 83 & 110.24 & 24.98 & & \\
\hline & \multirow{2}{*}{ Son Test } & Erkek & 66 & 121.39 & 26.92 & \multirow{2}{*}{-2.246} & \multirow{2}{*}{$.025 *$} \\
\hline & & Kadın & 83 & 112.02 & 25.10 & & \\
\hline \multirow{4}{*}{ Otur Uzan Eriş } & \multirow{2}{*}{ Ön Test } & Erkek & 66 & 2.76 & 3.78 & \multirow{2}{*}{-2.728} & \multirow{2}{*}{$.006 *$} \\
\hline & & Kadın & 83 & 4.22 & 4.72 & & \\
\hline & \multirow{2}{*}{ Son Test } & Erkek & 66 & 4.02 & 4.21 & \multirow{2}{*}{-2.905} & \multirow{2}{*}{$.004 *$} \\
\hline & & Kadın & 83 & 6.18 & 4.99 & & \\
\hline \multirow{4}{*}{$\begin{array}{l}\text { Sağlık Topu } \\
\text { Fırlatma }\end{array}$} & \multirow{2}{*}{ Ön Test } & Erkek & 66 & 283.18 & 75.51 & \multirow{2}{*}{-2.282} & \multirow{2}{*}{$.023 *$} \\
\hline & & Kadın & 83 & 261.33 & 73.79 & & \\
\hline & \multirow{2}{*}{ Son Test } & Erkek & 66 & 290.45 & 72.31 & \multirow{2}{*}{-1.142} & \multirow{2}{*}{.253} \\
\hline & & Kadin & 83 & 282.53 & 76.99 & & \\
\hline
\end{tabular}

$* \mathrm{p}<0,05$

Tablo 2'de görüldüğü üzere, Durarak uzun atlama becerisinde son test değerlerinde cinsiyete göre istatistiksel olarak anlamlı bir farka rastlanmıştır $(\mathrm{p}<0,05)$. Aritmetik ortalamalar incelendiğinde bu farkın erkek katılımcılar lehine olduğu belirlenmiştir.

Otur uzan eriş ön test ve son test değerlerinde cinsiyete göre istatistiksel olarak anlamlı bir farka rastlanmıştır $(\mathrm{p}<0,05)$. Fakat erişi değeri üzerinden değerlendirildiğinde erkeklerde erişi değeri $=1,26$ kadınlarda erişi değeri= 1,96 oranında gelişim sağlandığ 1 görülmüştür.

Sağlık topu firlatma ön test değerlerinde cinsiyete göre istatistiksel olarak anlamlı bir farka rastlanmıştır $(p<0,05)$. Fakat erişi değeri üzerinden değerlendirildiğinde erkeklerde erişi değeri= 7,27 kadınlarda erişi değeri= 21,2 oranında gelişim sağlandığı görülmüştür.

Tablo 3. Farklı değişkenlerin ön test son test değerlendirme tablosu sonuçları

\begin{tabular}{|c|c|c|c|c|c|c|}
\hline Değişken & & $\mathbf{N}$ & Ort. & SS & $\mathbf{Z}$ & $\mathbf{p}$ \\
\hline \multirow{2}{*}{ Durarak Uzun Atlama } & Ön Test & 149 & 112.68 & 25.95 & \multirow{2}{*}{-2.192} & \multirow{2}{*}{$.028 *$} \\
\hline & Son Test & 149 & 116.17 & 26.25 & & \\
\hline \multirow{2}{*}{ Otur Uzan Eriş } & Ön Test & 149 & 3.57 & 4.38 & \multirow{2}{*}{-5.019} & \multirow{2}{*}{$.000 *$} \\
\hline & Son Test & 149 & 5.22 & 4.77 & & \\
\hline \multirow{2}{*}{ Sağlık Topu Fırlatma } & Ön Test & 149 & 271.01 & 75.10 & \multirow{2}{*}{-3.236} & \multirow{2}{*}{$.001 *$} \\
\hline & Son Test & 149 & 286.04 & 74.81 & & \\
\hline
\end{tabular}

$* \mathrm{p}<0,05$

Tablo 3'de görüldüğü üzere, durarak uzun atlama, otur uzan eriş ve sağlık topu firlatma değişkenlerinde son testler lehine istatistiksel olarak anlamlı farklılık bulunmuştur $(\mathrm{p}<0,05)$. 


\section{TARTIŞMA ve SONUÇ}

Yapılan araştırmada, öğrencilerin oyun ve fiziki etkinlikler dersinin çocuklarda seçilmiş motorik özellikleri sonuçları cinsiyete göre karşılaştırıldığında, durarak uzun atlama becerisinde son test değerlerinde cinsiyete göre istatistiksel olarak anlamlı bir farka rastlanmıştır $(p<0,05)$. Aritmetik ortalamalar incelendiğinde bu farkın erkek katılımcılar lehine olduğu belirlenmiştir. Otur uzan eriş ön test ve son test değerlerinde cinsiyete göre istatistiksel olarak anlamlı bir farka rastlanmıştır $(p<0,05)$. Fakat erişi değeri üzerinden değerlendirildiğinde erkeklerde erişi değeri $=1,26$ kadınlarda erişi değeri $=1,96$ oranında gelişim sağlandığı görülmüştür. Sağlık topu firlatma ön test değerlerinde cinsiyete göre istatistiksel olarak anlamlı bir farka rastlanmıştır $(p<0,05)$. Fakat erişi değeri üzerinden değerlendirildiğinde erkeklerde erişi değeri $=7,27$ kadınlarda erişi değeri $=21,2$ oranında gelişim sağlandığı görülmüştür.

Durarak uzun atlama, otur uzan eriş ve sağlik topu firlatma parametrelerinde son testler lehine istatistiksel olarak anlamlı farklılık bulunmuştur $(p<0,05)$. Bu bağlamda cinsiyet ayrımı yapılmadan çocuklara uygulanan oyun ve fiziksel etkinliklerin sonucunda gelişim düzeylerine baktığımızda çocukların seçilen motorik özelliklerinde geliştiklerini görmekteyiz. Oyun ve fiziksel etkinliklerin çocuklarda kaba motor becerilerini olması gerekenden daha ileri seviyede geliştirdiğini literatürler doğrultusunda söyleyebiliriz.

Soğat (2007) sportif aktivitelerin 11-12 yaş grubu çocukların bedensel gelişimlerinde etkin bir rol oynadığı belirlenmiştir. Buna göre sportif aktivitelerin çocukların boy ve kilo gelişimlerini anlamlı düzeyde etkilediği tespit edilmiştir. Koçak ve Kartal (2003), yaptıkları çalışmada ilköğretim okullarında uygulanan müfredat programındaki beden eğitimi derslerinin öğrencinin fiziksel gelişimine olan etkisini araştırmışlar ve araştırma sonucunda uygulanmakta olan beden eğitimi ders etkinliklerinin istenen ölçüde öğrencilerin fiziksel uygunluklarında anlamlı gelişmelere yol açmadığını belirtmişlerdir. Kuru ve Köksalan (2012), yaptıkları 9 yaş çocuklarının psiko-motor gelişimlerinde oyunun etkisi araştırmasında müfredat dahilinde oynatılan oyunların, çocukların kaba motor becerilerini olması gerekenden daha ileri seviyede geliştirdiği; kız çocukları ile erkek çocuklarının ince motor beceriye bağlı olan top tutma becerisinde kızların lehine ayrıştıkları; durma becerisinde oyunun, (veri ortalamalarına göre) anlamlı farklılık çıkmayacak kadar geliştirilmesi zor bir beceri olduğu ve bu becerisinin sadece psiko-motor becerilerle ilgili olmayıp alg1, sinir sistemi ile alakalı olduğu sonucuna varılmıştır. Saygın, Polat ve Karacabey (2005), 10-12 yaş erkek çocuklara (80 deney ve 122 kontrol) 16 hafta süresince düzenli ve uzun süreli uygulanan hareket eğitiminin sonucunda, 10-12 yaş grubu çocuklarda fiziksel uygunluk özelliklerinin anlamlı düzeyde geliştiğini belirtmişlerdir. Van Beurden, Zask, Barnett ve Dietrich (2002), temel hareket becerileri için seçilmiş antrenman programının ilkokul dönemindeki çocuklarda motor beceriyi artırdığını göstermişlerdir. Şen (2004) çalışmasında, koşu ve durarak uzun atlama testlerinin ön test - son test değerleri arasında istatistiksel olarak anlamlı farklılıklar bulmuştur. Berg et al., (1995) sedanter ve sporcu çocuklar arasında birçok fiziksel ve antropometrik farklılıklar bulunmasına karşın, esneklik parametresinde anlamlı farklılık bulamamıştır. Kerkez ve ark., (2001) 11 yaş çocukların esnekliklerini 13,73 olarak bulmuşlardır. Loko et al. (2000) düzenli egzersiz yapan 10-17 yaş çocukların kendi yaş ve cinsteki çocuklardan daha kuvvetli ekstansör kaslara sahip olduklarını belirtmişlerdir. 
Faigenbaum et al. (2002) 11,5 yaş grubu çocuklara uyguladığı hareket ve kuvvet eğitimi sonucunda 1 RM ve maksimal kuvvette anlamlı gelişmeler bulduklarını ifade etmişlerdir. Planlı oyun aktivitelerinin motor becerilerinin gelişimine etkisi Tyson (1998) tarafindan araştırılmış ve 138 denek üzerinde ilk ve son test şeklinde motor test ölçümleri yapılmıştır. Sonuçta deney grubunun motor yeterliliğinde önemli bir artış gözlemlendiği ifade edilmiştir (Watts et al. 2003: 420-4).

Çalışma konusunda sınırlı araştırmalar bulunsa da, araştırmaların sonuçları çeşitlilik arz eden oyun ve fiziki etkinliklerin okul çocuklarında motor gelişimi olumlu etkilediğini göstermiştir. $\mathrm{Bu}$ bağlamda farklı beceriler içeren sportif etkinlik programlarını motor gelişim yönünden inceleyen bu çalışmalar araştırmamız ile paralellik göstermektedir.

Sonuç olarak, oyun ve fiziki etkinlikler dersi kapsamında uygulanan sportif etkinlikler içeren hareket eğitiminin ilköğretim birinci kademesindeki çocuklarda psikomotor gelişimini pozitif yönde etkilediği görülmüştür. Motor beceriyi oluşturan temel hareket modellerine uygun sportif etkinlikler uygulanması motor beceri gelişimi açısında olumlu bir farklılık yaratmıştır. Bu çalışmanın sonuçları doğrultusunda, seçilen yaş grubunun özellikle sportif uzmanlaşma döneminin ilk evresinde bulunması çalışmanın önemini ortaya koymaktadır. Bu dönemdeki çocuklarda sportif etkinlikler fiziksel ve nörölojik özelliklerine göre planlanmalı, farklı becerileri kazandıracak hareket fırsatları verilmelidir. Bu bilgiler 1şığında bu yaş grubuna yönelik yapılan oyun ve fiziki etkinlikler dersi kapsamında uygulanan sportif etkinlikler daha fonksiyonel hazırlanmalıdır. Kontrol gruplu bir deney deseni oluşturularak yapılacak beceri uygulamasının çocukların psikomotor gelişimi ne derece etkisinin olduğu ortaya konulabilir.

\section{KAYNAKLAR}

Altınkök, M., Vazgeçer, E., ve Ölçücü, B. (2013). Temel motor hareketlerin geliştirilmesini içeren beden eğitimi program tasarısının 5-6 yaş çocukların temel motor hareketlerinin gelişimine etkisinin araştırılması. Uluslararası Türk Ĕ̈itim Bilimleri Dergisi, 1(1), 74-87.

Berg, K. E., LaVoie, J. C., \& Latin, R. W. (1995). Physiological training effect of youht soccer. Med. Sci. Sports Exerc. Dec, 17(6), 656-60.

Çelik, A. (2016). Hareket eğitimi koordinatif yetiler ve temel becerilerin eğitimi. İstanbul: Ergün yayınevi, s.180-181.

Çelik, A., ve Şahin, M. (2013). Spor ve çocuk gelişimi. The Journal of Academic Social Science Studies JASSSInternational Journal of Social Science, 6(1), 467-478.

Demirci, N., ve Demirci, P. T. (2014). Özel eğitime gereksinim duyan öğrencilerin oyun ve fiziki etkinlikler dersinde elde ettikleri kazanimlarin incelenmesi. İп̈nӥ Üniversitesi Beden Eğitimi ve Spor Bilimleri Dergisi, 1(1), 25-34.

Faigenbaum, A. D., Milliken, L. A., Loud, R. L., Burak, B. T., Doherty, C. L., \& Westcott, W. L. (2002). Comparison of 1 and 2 days per week of strength training in children. Research quarterly for exercise and sport, 73(4), 416-424. 
Gray, T. A., \& Judy, O. (2003). Physical education rec. And Dance, 74(6), 52.

Gülüm, V. (2008). Adana ilindeki beden ĕgitimi öğretmenlerinin ilköğretim okullarında uygulanmakta olan beden ĕgitimi öğretim programına yönelik görüşlerinin dĕgerlendirilmesi. (Yayınlanmamış) Yüksek Lisans Tezi, Çukurova Üniversitesi Sağlık Bilimleri Enstitüsü Beden Eğitimi ve Spor Anabilim Dalı., 7.

Ishee, J. A. (2003). Participation in extracurricular physical in middle schools. Journal of Physical Education, Recreation \& Dance, 74(4), 10.

Kerkez F., Kalkavan A. ve Öztürk A. (2001). Bazı psikomotor ve fiziksel özellilerin koordinatif yeteneğe etkisinin van’lı 9-11 yaş grubu erkek çocukların üzerinde araştırılması. Spor Araştırmaları Dergisi, 5(1), 9-27.

Koç, H., ve Tekin, A. (2011). Beden eğitimi derslerinin çocuklarda seçilmiş motorik özellikler üzerine etkisi. VAN/YYÜ Ĕ̈itim Fakültesi Dergisi Özel Sayısı, 9-17

Koçak, S, ve Kartal, A, (2003). İlköğretim öğrencilerinin bir öğretim döneminde fiziksel uygunluk gelişimlerindeki değişimin incelenmesi. Gazi Beden Ĕ̌itimi ve Spor Bilimleri Dergisi, 8 (1), 53-60.

Kuru, O., ve Köksalan, B. (2012). 9 yaş çocuklarının psiko-motor gelişimlerinde oyunun etkisi. Cumhuriyet International Journal of Education, 1(2), 37-49.

Loko, J., Aule, R., Sikkut, T., Ereline, J., \& Viru, A. (2000). Motor performance status in 10 to 17-year-old Estonian girls. Scandinavian journal of medicine \& science in sports, 10(2), 109-113.

Saygın, Ö., Polat, Y., ve Karacabey, K. (2005). Çocuklarda hareket eğitiminin fiziksel uygunluk özelliklerine etkisi. Fırat Üniversitesi Să̆llk Bilimleri Dergisi, 19(3), 205-212.

Şen, M. (2004) Anaokuluna devam eden altı yaş çocukların motor gelişimlerine beden eğitimi çalışmalarının etkisinin incelenmesi. (Yayınlanmamış) Yüksek Lisans Tezi, Ankara Üniversitesi, Fen Bilimleri Enstitüsü, Ankara.

Soğat, A. (2007). Spor yapan ve yapmayan 11-12 yaş grubu çocuklarda bazı fiziksel özelliklerin araştırllması. (Yayımlanmamış) Yüksek Lisans Tezi, Dumlupınar Üniversitesi Sosyal Bilimler Enstitüsü, Kütahya.

Van Beurden, E., Zask, A., Barnett, L.M., \& Dietrich, U.C. (2002). Fundamental movement skills- how do primary school children perform? The "move it groove it" program in rural Australia. J Sci Med Sport, 5, 244-52.

Watts, P.B., Joubert, L.M., Lish, A.K., Mats, J.D., \& Wilkins, B. (2003). Anthropometry of young competitive sport rock climbers. Br Journal Sport Medicine, 37, 420-4

Yüzgül A. ve Müniroğlu S. (2001). Ankara'da özel bir okulda 7-12 yaş grubu çocukların fiziksel özelliklerinin incelenmesi. 3. Uluslararası Akdeniz Spor Bilimleri Kongresi bildiriler kitabı içinde (ss. 343-356) Antalya. 